\title{
Differential Strategies to Tolerate Flooding in Polygonum hydropiper Plants Originating From Low- and High-Elevation Habitats
}

\author{
Xin-Sheng Chen ${ }^{1,2 * t}$, Ya-Fang Li ${ }^{1,2+}$, Yun-He Cai ${ }^{3}$, Yong-Hong Xie ${ }^{1,2 *}$, \\ Zheng-Miao Deng ${ }^{1,2}$, Feng $\mathrm{Li}^{1,2}$ and Zhi-Yong Hou ${ }^{1,2}$ \\ 1 Key Laboratory of Agro-ecological Processes in Subtropical Region, The Chinese Academy of Sciences, Changsha, China, \\ 2 Dongting Lake Station for Wetland Ecosystem Research, Institute of Subtropical Agriculture, The Chinese Academy \\ of Sciences, Changsha, China, ${ }^{3}$ The Faculty of Geography and Resources Sciences, Sichuan Normal University, Chengdu, \\ China
}

OPEN ACCESS

Edited by:

Henry D. Adams,

Oklahoma State University,

United States

Reviewed by:

Chunhua Liu,

Wuhan University, China

Núria Garcia-Forner,

Universidade de Coimbra, Portugal

*Correspondence:

Xin-Sheng Chen

xschen@isa.ac.cn

Yong-Hong Xie

yonghongxie@163.com

${ }^{\dagger}$ These authors have contributed equally to this work

Specialty section:

This article was submitted to

Functional Plant Ecology,

a section of the journal

Frontiers in Plant Science

Received: 04 September 2018 Accepted: 19 December 2018

Published: 09 January 2019

Citation:

Chen X-S, Li Y-F, Cai Y-H, Xie Y-H, Deng Z-M, Li F and Hou Z-Y (2019)

Differential Strategies to Tolerate

Flooding in Polygonum hydropiper Plants Originating From Lowand High-Elevation Habitats.

Front. Plant Sci. 9:1970.

doi: 10.3389/fp/s.2018.01970
In species that occur over a wide range of flooding conditions, plant populations may have evolved divergent strategies as a consequence of long-term adaptation to local flooding conditions. In the present study, we investigated the effects of a flooding gradient on the growth and carbohydrate reserves of Polygonum hydropiper plants originating from low- and high-elevation habitats in the Dongting Lake wetlands. The results indicated that shoot length did not differ, whereas the total biomass and carbohydrate reserves were reduced under flooded compared to well-drained conditions for plants originating from both habitat types. However, shoot length, shoot mass, rhizome mass, and total biomass were lower in plants from low-elevation habitats than in those from high-elevation habitats in the flooded condition. Soluble sugar and starch contents in belowground biomass were higher in plants from low-elevation habitats than in those from high-elevation habitats independently of the water level. Therefore, $P$. hydropiper plants from low-elevation habitats exhibit a lower growth rate and more conservative energy strategy to cope with flooding in comparison with plants from high-elevation habitats. Differential strategies to cope with flooding among P. hydropiper populations are most likely a response to the flooding pressures of the habitat of origin and may potentially drive ecotype differentiation within species along flooding gradients.

Keywords: local adaptation, flooding tolerance, carbohydrate storage, phenotypic plasticity, ecotype differentiation

\section{INTRODUCTION}

Flooding is considered to be a major determining factor in plant growth and species distribution in riparian and lacustrine wetlands (van Eck et al., 2004; Dwire et al., 2006; Luo et al., 2008). Flooding constrains the growth of emergent macrophytes mainly by reducing oxygen availability, ranging from deficiency (hypoxia) to absence (anoxia) of oxygen in highly reduced soils (Vervuren et al., 2003). 
The strategies of plants to cope with flooding-induced low oxygen can be categorized as the escape strategy and the quiescence strategy (Bailey-Serres and Voesenek, 2008, 2010; Striker et al., 2012). In the escape strategy, the plant grows and/or elongates its shoot to reach the surface and restore contact with the atmosphere (Bailey-Serres and Voesenek, 2008; Manzur et al., 2009). However, the process of shoot elongation is costly under low-oxygen conditions, i.e., the energy required for growing tissues would lead to faster carbohydrate depletion by anaerobic metabolism (Bailey-Serres and Voesenek, 2008, 2010). In contrast, the quiescence strategy is characterized by stable functional traits, such as minimum growth and conservation of carbohydrate reserves (Setter and Laureles, 1996; Sauter, 2000; Bailey-Serres and Voesenek, 2008).

The escape strategy is proposed to be beneficial only in shallow and prolonged floods, where shoot de-submergence is generally possible (Pierik et al., 2009; Chen et al., 2011; Striker et al., 2012). The quiescence strategy is speculated to be beneficial in deep and temporary floods, where shoot emergence might incur higher energy cost and affect eventual recovery when water recedes (Colmer and Voesenek, 2009; Akman et al., 2012; Striker et al., 2012). Along the elevational gradient in wetlands, flood duration and flood depth are highly associated, i.e., plants distributed at high-elevation sites usually experience shallow and temporary flooding, while plants distributed at low-elevation sites often experience deep and long-lasting flooding. This raises the question whether plant populations experiencing deep and prolonged flooding exhibit the quiescent strategy, and plant populations experiencing shallow and temporary flooding use the escape strategy.

Generally, whether plant species exhibit the escape or the quiescence strategy depends on genetics and the flooding regimes in their natural habitats (Akman et al., 2012; Striker et al., 2012). For example, Rorippa amphibia (L.) Besser, occupying habitats with long-lasting and relatively shallow floods, adopts the escape strategy and Rorippa sylvestris (L.) Besser, occupying habitats with deeper and transient floods, adopts the quiescence strategy (Akman et al., 2012). However, some species occur over a large range of flooding conditions. It is estimated that approximately $30 \%$ of the common trees of the Amazonian floodplains also grow in non-flooded upland forests (Ferreira et al., 2009). With longterm adaptation to local flooding conditions, plant populations may have evolved divergent survival and tolerance strategies to cope with distinct flooding regimes (Chen et al., 2009; Ferreira et al., 2009; Mollard et al., 2010). However, few experimental studies have found significant differences in flooding tolerance strategies among populations (Lenssen et al., 2004; Li et al., 2016; Zhang et al., 2016).

In the present study, we investigated the effect of flooding gradients on the growth and carbohydrate reserves of Polygonum hydropiper (L.) Delarbre plants originating from two habitats with contrasting flooding conditions in the Dongting Lake wetlands. Polygonum hydropiper grows along flooding gradients from low-elevation, lakeside habitats to high-elevation, landside habitats. We hypothesized that $P$. hydropiper from low-elevation sites would utilize the quiescence strategy to survive deep and prolonged flooding, whereas $P$. hydropiper from high-elevation sites would employ the escape strategy to survive shallow and temporary flooding. Hence, morphological traits and the contents of non-structural carbohydrates (i.e., soluble sugars and starch) of $P$. hydropiper plants collected from these two habitat types were evaluated in relation to four water table levels; specifically, drained (water level at $-15 \mathrm{~cm})$, waterlogged $(0 \mathrm{~cm})$, semi-submergence $(15 \mathrm{~cm})$, and complete submergence $(30 \mathrm{~cm})$.

\section{MATERIALS AND METHODS}

\section{Study Species}

Polygounum hydropiper (Polygonaceae) is distributed along the sides of streams and riverbanks, and in wet valleys in temperate and subtropical regions of Asia, Australia, Europe, and North America (Li et al., 2003). The branched stems of $P$. hydropiper are normally $40-70 \mathrm{~cm}$ long. It is described as an annual herb (Li et al., 2003), but it produces overwintering belowground rhizomes in the Dongting Lake wetlands (Chen et al., 2014, 2015; Pan et al., 2014). Polygonum hydropiper is one of the dominant species in the Dongting Lake wetlands and is usually distributed adjacent to the water body and extends to the embankment (Xie and Chen, 2008).

\section{Experimental Design}

The experiment was conducted using wild plants growing in a monitoring plot of the Dongting Lake Station for Wetland Ecosystem Research of the Chinese Academy of Sciences (Yueyang, Hunan, China). On February 10, 2014, plant cuttings of $P$. hydropiper from a low-elevation site $\left(29^{\circ} 27^{\prime} 42.52^{\prime \prime} \mathrm{N}, 112^{\circ} 47^{\prime} 30.09^{\prime \prime} \mathrm{E}, 25.0 \mathrm{~m}\right.$ a.s.l. $)$ and a highelevation site $\left(29^{\circ} 27^{\prime} 54.79^{\prime \prime} \mathrm{N}, 112^{\circ} 46^{\prime} 30.67^{\prime \prime} \mathrm{E}, 29.4 \mathrm{~m}\right.$ a.s.l.) along a small-scale elevational gradient in the monitoring plot were collected and transported to the Dongting Lake Station for Wetland Ecosystem Research. Although these two sites differed only by $4.4 \mathrm{~m}$ in elevation and were located $\sim 1.6 \mathrm{~km}$ apart, they have important differences in flooding regime. In 2014, the lowand high-elevation sites were submerged during 194 and 71 days, respectively, and mean flooding depths were $3.47 \pm 1.84 \mathrm{~m}$ (mean $\pm \mathrm{SD}$ ) and $0.98 \pm 0.87 \mathrm{~m}$, respectively, at the sampling sites.

Plant cuttings were planted at a depth of approximately $5 \mathrm{~cm}$ in a nursery bed containing a soil/sand mixture $(1: 1 \mathrm{v} / \mathrm{v})$. The soil was collected from the upper layer of the plant collection site and contained $0.19 \%$ total nitrogen and $0.08 \%$ total phosphorus. After the establishment of plants from the cuttings, on April 6, 80 similar-sized plants (40 plants per habitat type) were selected, planted into individual PVC tubes (height, $30 \mathrm{~cm}$; diameter, $30 \mathrm{~cm}$ ) that were filled with $30 \mathrm{~cm}$ soil, and allowed to grow. On April 20, 48 similar-sized plants (24 plants per habitat type, $28-30 \mathrm{~cm}$ in height) were selected for the experiment.

The experimental design was a randomized block with six replicates; the experiment was performed in six outdoor water tanks $(100 \times 100 \times 100 \mathrm{~cm})$ with eight plants (one plant per habitat type per water level) in each tank. The water level in the tanks was maintained at $60 \mathrm{~cm}(30 \mathrm{~cm}$ above the soil surface in the $30-\mathrm{cm}$ water-level treatment). Different water-level 
treatments within a water tank were established by placing the PVC tubes on either the bottom of the tank $(0 \mathrm{~cm})$ or on concrete benches at different heights $(15,30$, and $45 \mathrm{~cm})$. The plants placed on the bottom of the tank and on the $15-\mathrm{cm}$ concrete benches were regarded as flooded plants. The plants placed on the 30 - and $45-\mathrm{cm}$ concrete benches were regarded as waterlogged ( $0 \mathrm{~cm}$ for the plants) and well-drained $(-15 \mathrm{~cm}$ for the plants) plants, respectively. Water in the tank was replaced monthly, and filamentous algae were removed manually at regular intervals.

The plants were harvested on August 18, 120 days after the treatment was started, which is more than half of the flooding duration in the low-elevation site. The plants were carefully removed from the tubes to keep the roots and rhizome structures intact. The plants were then cleaned with tap water and transferred to the laboratory for measurements. The branches and rhizomes were counted. Shoot length was calculated as the distance from the shoot base to the tip of the longest leaf. Each plant was then separated into shoots, roots, and rhizomes. The biomass of each plant part was measured after drying in an oven at $80^{\circ} \mathrm{C}$ for $48 \mathrm{~h}$. Total biomass was determined as the total plant dry weight at the end of the experiment.

The contents of starch and soluble sugar were analyzed using a modification of the method of Yemm and Willis (1954). The dry belowground biomass including roots and rhizomes of each plant was ground to a fine powder and extracted three times using $80 \%$ ethanol $(\mathrm{v} / \mathrm{v})$. Then, $0.5 \mathrm{ml}$ of anthrone reagent and $5 \mathrm{ml}$ oil of vitriol were added to the extract. The mixture was heated for $10 \mathrm{~min}$ in boiling water and then cooled quickly in an ice bath, followed by measurement of the absorbance at $630 \mathrm{~nm}$ using a spectrophotometer (Shimadzu, Kyoto, Japan). The residue remaining after soluble sugars extracted was dried, extracted with $30 \%$ perchloric acid, and analyzed for starch (as glucose equivalent) by spectrophotometry using the anthrone reagent.

\section{Statistical Analyses}

The significance of differences in total biomass, shoot length, numbers of branches and rhizomes, and of the contents of soluble sugar and starch of plants from the two habitat types under different water-level treatments was assessed using general linear models, with water level and habitat type included as main factors and block as a random factor (McKone and Lively, 1993). We further conducted linear contrasts to test the effect of water level in each plant habitat type, and the effect of plant habitat type at each water level. The least significant difference (LSD) method was used to compare means among the four water-level treatments (Sokal and Rohlf, 1981). Data were $\log _{10}$-transformed if necessary to reduce the heterogeneity of variances, and heterogeneity was confirmed using Levene's test. All statistical analyses were performed using SPSS 15.0 (SPSS Inc., Chicago, IL, United States).

\section{RESULTS}

\section{Plant Biomass}

Total biomass, shoot mass, and rhizome mass produced by $P$. hydropiper were significantly affected by habitat type and water level (Table 1). The total biomass and rhizome mass of $P$. hydropiper plants were significantly lower in the flooding treatments (15- and $30-\mathrm{cm}$ water levels) than in the welldrained treatment $(-15-\mathrm{cm}$ water level) (Figures 1A,D). The shoot mass was significantly lower in the flooding treatments than in the well-drained treatment for plants from the lowelevation habitat, but not for plants from the high-elevation habitat (Figure 1B). In the 30-cm flooding treatment, plants from the high-elevation habitat produced higher shoot mass, rhizome mass, and total biomass than those from the low-elevation habitat (Figures 1A,B,D).

Root mass produced by $P$. hydropiper was significantly affected by habitat type and water level, with significant interactions between both factors (Table 1). Root mass was significantly lower in the $30-\mathrm{cm}$ flooding treatment than that in the well-drained treatment (Figure 1C). Root mass was higher in plants from the high-elevation habitat than in those from the low-elevation habitat, except at 30-cm water level (Figure 1C).

\section{Shoot Length, Number of Branches, and Rhizomes}

Shoot length of $P$. hydropiper plants was only significantly affected by habitat type (Table 1 and Figure 2A). In the -15and $30-\mathrm{cm}$ water-level treatments, shoot length was higher in plants from the high-elevation habitat than in those from the low-elevation habitat. The number of rhizomes produced by $P$. hydropiper was significantly affected by water level (Table $\mathbf{1}$ and Figure 2B). Polygonum hydropiper plants in the $15-\mathrm{cm}$ flooding treatment produced less rhizomes than plants in the well-drained $(-15-\mathrm{cm}$ water level) condition. The number of branches produced by $P$. hydropiper was neither affected by water level nor by habitat type (Table 1 and Figure 2C).

TABLE 1 | Summary of two-way analysis of variance ( $F$-values) for shoot mass, root mass, rhizome mass, and total biomass; shoot length; branch and rhizome numbers; and the contents of soluble sugar and starch in $P$. hydropiper from two habitat types under four water levels.

\begin{tabular}{|c|c|c|c|c|c|c|c|c|c|}
\hline Effect & $\begin{array}{l}\text { Total } \\
\text { biomass }\end{array}$ & $\begin{array}{l}\text { Shoot } \\
\text { mass }\end{array}$ & Root mass & $\begin{array}{l}\text { Rhizome } \\
\text { mass }\end{array}$ & $\begin{array}{l}\text { Shoot } \\
\text { length }\end{array}$ & $\begin{array}{l}\text { Number of } \\
\text { branches }\end{array}$ & $\begin{array}{l}\text { Number of } \\
\text { rhizomes }\end{array}$ & $\begin{array}{l}\text { Starch } \\
\text { content }\end{array}$ & $\begin{array}{l}\text { Water- } \\
\text { soluble } \\
\text { sugar }\end{array}$ \\
\hline Habitat type $(\mathrm{H})$ & $11.94^{* *}$ & $4.29 *$ & $37.47^{* * *}$ & $17.33^{* * *}$ & $18.35^{* * *}$ & $0.22^{\mathrm{ns}}$ & $0.09^{n s}$ & $68.03^{* * *}$ & $137.91^{* * *}$ \\
\hline Water level (N) & $18.78^{* * *}$ & $5.60^{* *}$ & $14.35^{* * *}$ & $35.56^{* *}$ & $0.45^{\text {ns }}$ & $2.54^{\mathrm{ns}}$ & $3.74^{*}$ & $10.23^{* * *}$ & $14.39 * * *$ \\
\hline $\mathrm{H} \times \mathrm{N}$ & $0.56^{\mathrm{ns}}$ & $2.13^{\text {ns }}$ & $3.00^{*}$ & $0.22^{\text {ns }}$ & $1.28^{\mathrm{ns}}$ & $0.51^{\mathrm{ns}}$ & $0.13^{\mathrm{ns}}$ & $2.46^{\mathrm{ns}}$ & $0.95^{\mathrm{ns}}$ \\
\hline
\end{tabular}

${ }^{* * *} P<0.001 ;{ }^{* *} P<0.01{ }^{*} P<0.05 ;{ }^{n s} P>0.05$ 

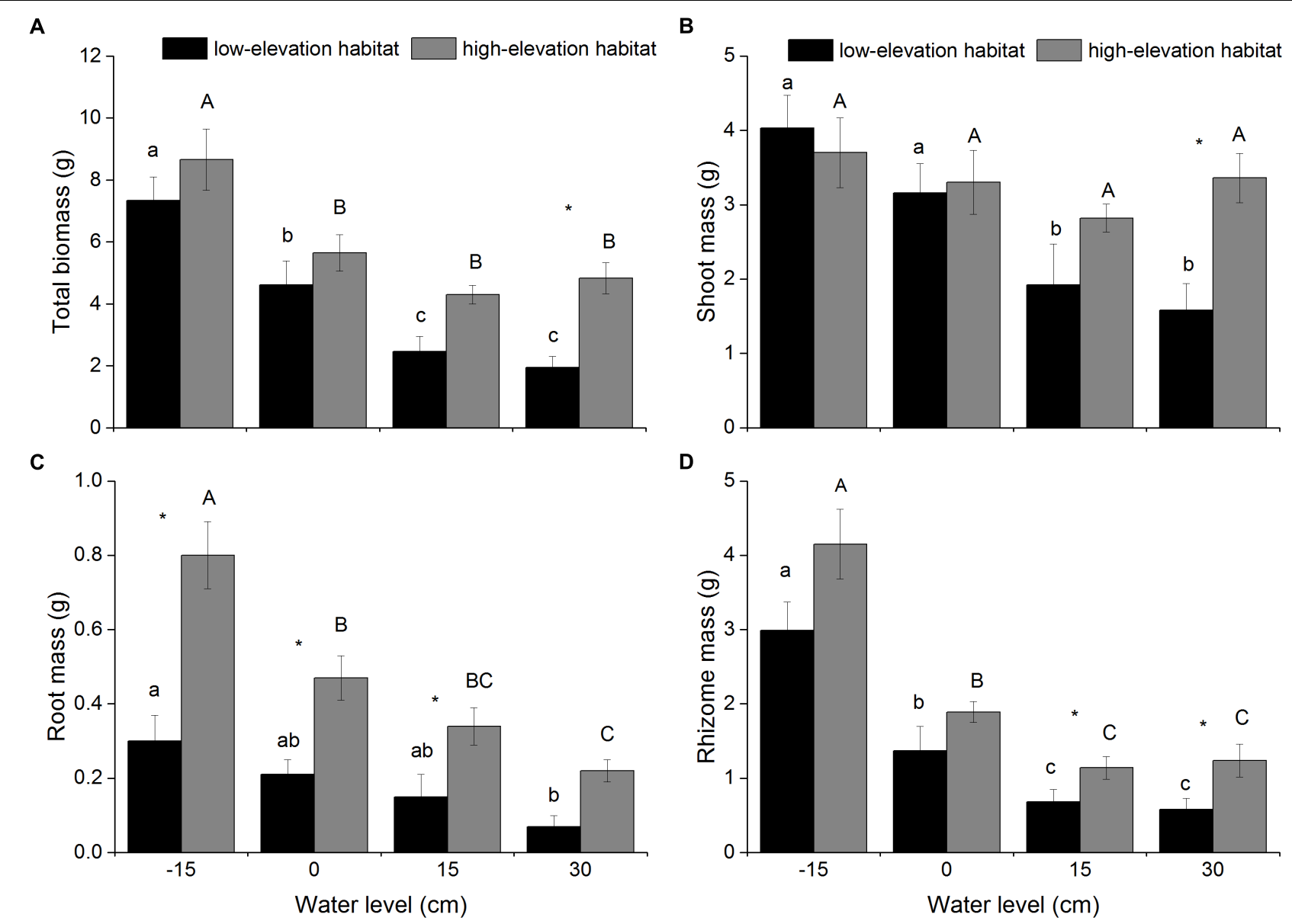

FIGURE 1 | Total biomass (A), shoot mass (B), root mass (C), and rhizome mass (D) of $P$. hydropiper plants originating from two habitats grown under four water levels. Different lower-case or capital letters indicate that means differ significantly between the water-level treatments for plants originating from low-elevation and high-elevation habitats, respectively. Symbols $\left(^{*}\right)$ show which means differed between habitat types at each of the four water levels.

\section{Non-structural Carbohydrate Contents}

Soluble sugar and starch contents were significantly affected by habitat type and water level (Table 1). The soluble sugar content was lower in the flooding treatments (15- and 30-cm water levels) than in the waterlogged condition ( $0-\mathrm{cm}$ water level; Figure $3 \mathbf{A})$. The starch content was lower in the $30-\mathrm{cm}$ flooding treatment than in the well-drained and waterlogged treatments $(-15-$ and 0 -cm water level; Figure 3B). Soluble sugar and starch contents of plants from the low-elevation habitat were higher than those in plants from the high-elevation habitat at all water levels (Figures 3A,B).

\section{DISCUSSION}

Shoot length did not differ among flooding treatments for plants either from low-elevation or high-elevation habitats, indicating that $P$. hydropiper did not exhibit an apparent escape strategy to cope with flooding. Shoot elongation is considered an efficient approach for escaping submergence stress, and a key attribute in a low-oxygen escape strategy (Chen et al., 2009). However, elongation growth competes with maintenance processes for carbon used for survival during complete submergence (Ram et al., 2002). Moreover, if air contact cannot be established, high carbohydrate consumption will lead to an energy deficit, severe tissue damage, and mortality (Pierik et al., 2009; Chen et al., 2011). It was found that elongation growth by leaves is negatively correlated with seedling survival under complete submergence in rainfed lowland rice cultivars (Ram et al., 2002). In our flooding treatments, shoots of $P$. hydropiper emerged from the water. However, in their habitats of origin, flooding was deep and longlasting even for $P$. hydropiper populations in the high-elevation habitat (mean flood depth $0.98 \mathrm{~m}$ and 71 days). Elongation growth may not be sufficient for shoots of $P$. hydropiper to regain contact with the air, and therefore the escape strategy was not selected.

Flooding generally reduced the total biomass and carbohydrate reserve of $P$. hydropiper from both highelevation and low-elevation habitats. Emergent macrophytes like $P$. hydropiper have evolved a range of morphological and physiological adaptations, such as stem or petiole elongation, narrower and thinner leaves, short and thick roots, a shallow 


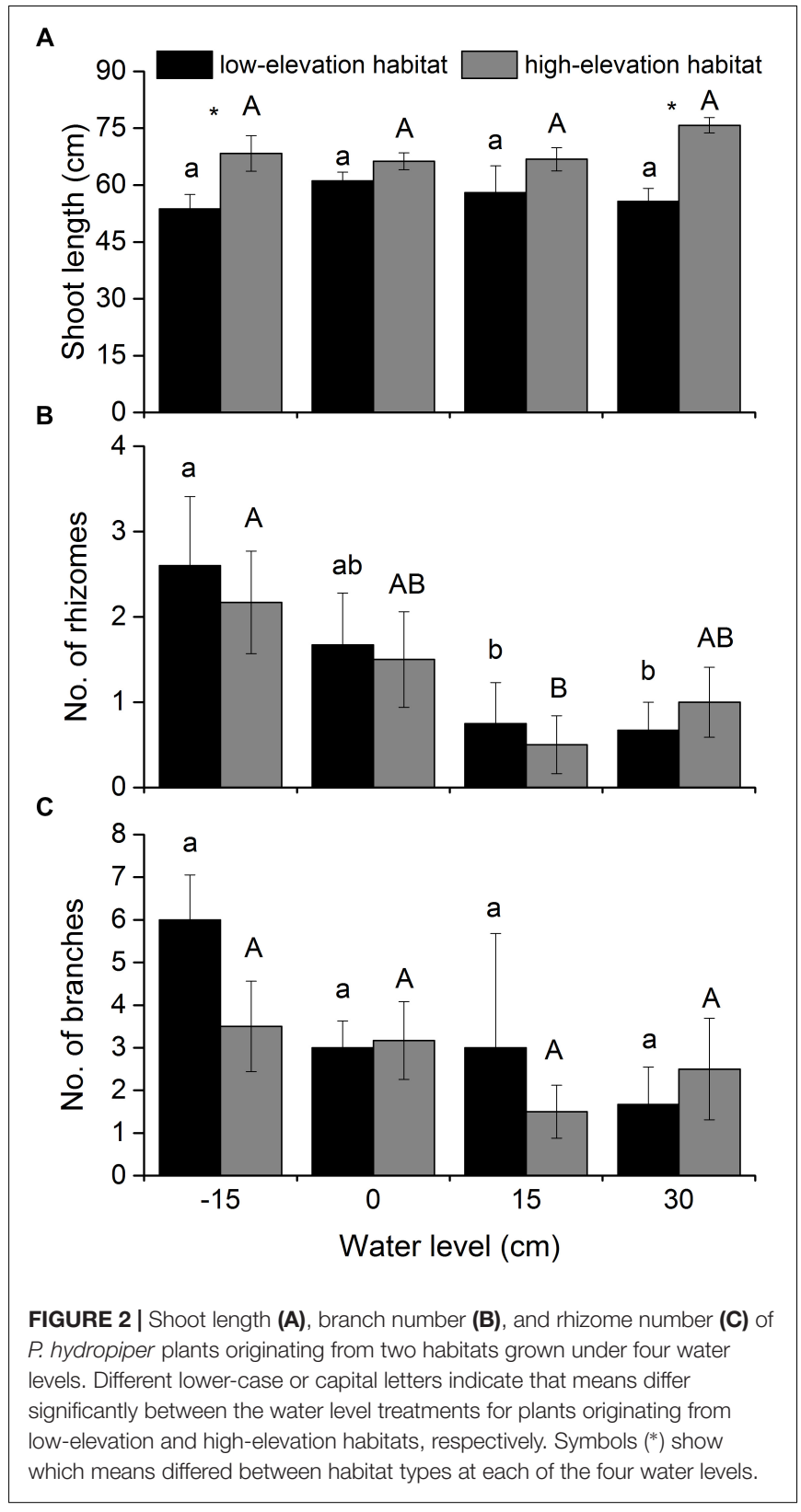

root system, aerenchyma formation, glycolysis, and fermentation to acquire oxygen or diminish root oxygen demand in flooded environments (Chen et al., 2009; Xie et al., 2009; Pan et al., 2014). However, emergent plants usually lack the ability to sustain photosynthetic activity when submerged in water (Macek et al., 2006). Extended periods of anoxic conditions may eventually result in the reduction of plant growth and total biomass (Edwards et al., 2003).

Although flooding generally reduced the growth of $P$. hydropiper plants from both habitat types, shoot length and total biomass in the $30-\mathrm{cm}$ flooding treatment were lower in plants from the low-elevation habitat than those from the high-elevation habitat. These results indicated that $P$. hydropiper plants from the low-elevation habitat exhibit a

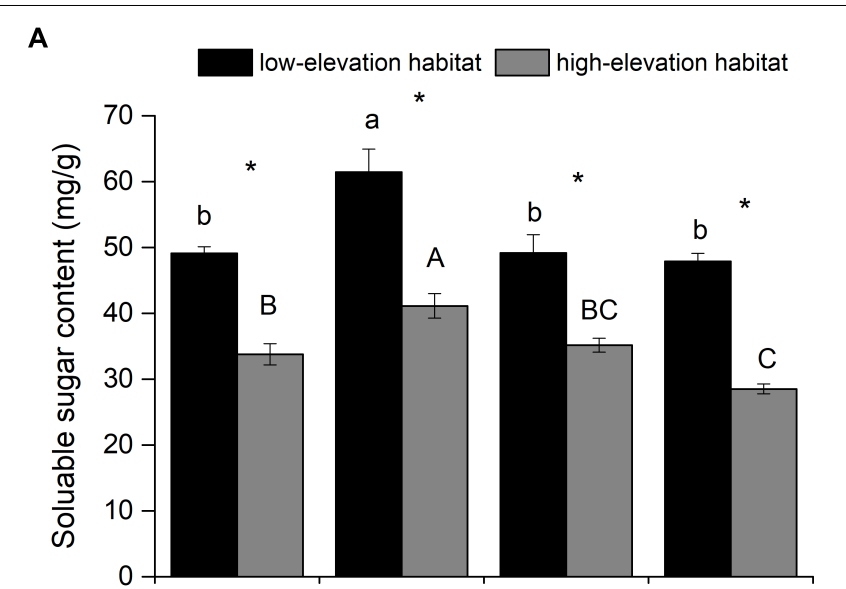

B

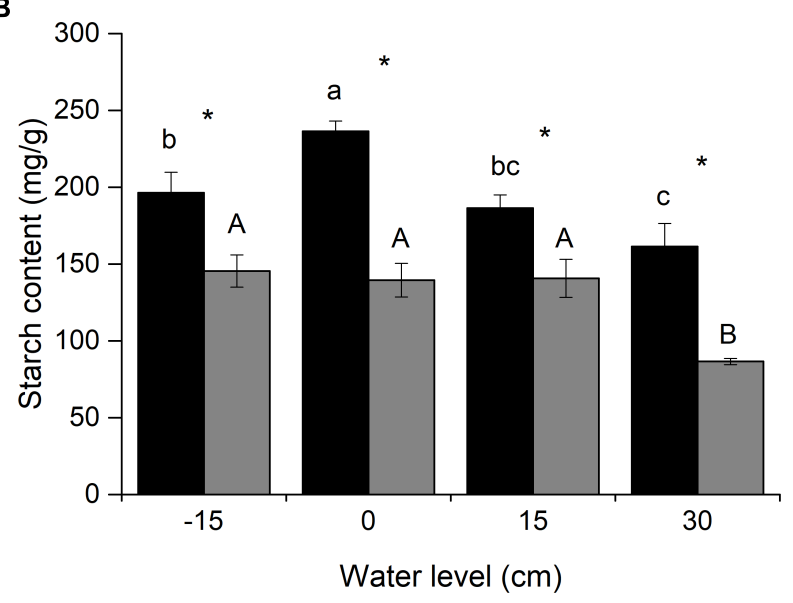

FIGURE 3 | Soluble sugar (A) and starch (B) contents in belowground biomass (roots and rhizomes) of $P$. hydropiper plants originating from two habitats grown under four water levels. Different lower-case or capital letters indicate that means differ significantly between the water level treatments for plants originating from low-elevation and high-elevation habitats, respectively. Symbols $\left(^{*}\right)$ show which means differed between habitat types at each of the four water levels.

smaller modular size and lower growth rate under complete submergence than plants from the high-elevation habitat. Previous studies have also found a reduced modular size in lakeside genotypes in comparison with landside genotypes of Ranunculus reptans L. (Lenssen et al., 2004). During submergence, a low growth rate and small modular size may result in lower respiratory losses and consequently, in high carbohydrate reserves (Lenssen et al., 2004). Consistent with this hypothesis, water-soluble sugar and starch contents were higher in $P$. hydropiper plants from the low-elevation habitat than in those from the high-elevation habitat. A high carbohydrate supply is related to flooding tolerance under complete submergence (Ram et al., 2002; Qin et al., 2013). Large carbohydrate reserves may enable $P$. hydropiper plants to tolerate deep and long-lasting flooding in low-elevation habitats. Therefore, differences in growth and carbohydrate reserves under complete submergence between plants from low- and 
high-elevation habitats are most likely a response to the flooding pressures of the habitat of origin.

Flooding can act as a strong selective pressure for key adaptations, potentially leading to ecotype differentiation or even speciation (Lenssen and de Kroon, 2005; Voesenek et al., 2006). Mollard et al. (2010) have shown that subtle topographical differences along a floodplain may promote different plant strategies among Paspalum dilatatum Poir. populations and drive within-species ecotype differentiation. Lenssen et al. (2004) reported that flooding can induce genetic differentiation in the clonal species $R$. reptans along a small-scale gradient. In the present study, $P$. hydropiper populations from habitats differing in flooding regimes exhibited different morphological and physiological responses to flooding, suggesting there is a potential for population differentiation along flooding gradients (Chen et al., 2009; Ferreira et al., 2009).

\section{CONCLUSION}

Our results indicated that flooding reduced growth and carbohydrate reserves of $P$. hydropiper plants originating from both high-elevation and low-elevation habitats. However, lowelevation and high-elevation populations of $P$. hydropiper respond differently to flooding disturbances. Under complete submergence, the low-elevation population showed a smaller modular size and lower growth rate in comparison with the

\section{REFERENCES}

Akman, M., Bhikharie, A. V., McLean, E. H., Boonman, A., Visser, E. J. W., Schranz, M. E., et al. (2012). Wait or escape? contrasting submergence tolerance strategies of Rorippa amphibia, Rorippa sylvestris and their hybrid. Ann. Bot. 109, 1263-1275. doi: 10.1093/aob/mcs059

Bailey-Serres, J., and Voesenek, L. A. (2008). Flooding stress: acclimations and genetic diversity. Annu. Rev. Plant Biol. 59, 313-339. doi: 10.1146/annurev. arplant.59.032607.092752

Bailey-Serres, J., and Voesenek, L. A. (2010). Life in the balance: a signaling network controlling survival of flooding. Curr. Opin. Plant Biol. 13, 489-494. doi: 10.1016/j.pbi.2010.08.002

Chen, X., Huber, H., de Kroon, H., Peeters, A., Poorter, H., Voesenek, L., et al. (2009). Intraspecific variation in the magnitude and pattern of flooding-induced shoot elongation in Rumex palustris. Ann. Bot. 104, 1057-1067. doi: 10.1093/ aob/mcp 198

Chen, X., Visser, E. J. W., de Kroon, H., Pierik, R., Voesenek, L. A., and Huber, H. (2011). Fitness consequences of natural variation in flooding-induced shoot elongation in Rumex palustris. New Phytol. 190, 409-420. doi: 10.1111/j.14698137.2010.03639.x

Chen, X. S., Deng, Z. M., Xie, Y. H., Li, F., Hou, Z. Y., and Li, X. (2015). Belowground bud banks of four dominant macrophytes along a small-scale elevational gradient in Dongting Lake wetlands. China Aquat. Bot. 122, 9-14. doi: 10.1016/j.aquabot.2014.12.006

Chen, X. S., Deng, Z. M., Xie, Y. H., Li, F., and Li, X. (2014). Differential growth and vegetative reproduction by two co-occurring emergent macrophytes along a water table gradient. Pak. J. Bot. 46, 881-886.

Colmer, T. D., and Voesenek, L. A. C. J. (2009). Flooding tolerance: suites of plant traits in variable environments. Funct. Plant Biol. 36, 665-681. doi: 10.1071/ FP09144

Dwire, K. A., Kauffman, J. B., and Baham, J. E. (2006). Plant species distribution in relation to water-table depth and soil redox potential in montane riparian meadows. Wetlands 26, 131-146. doi: 10.1672/0277-5212(2006) 26[131:PSDIRT]2.0.CO;2 high-elevation population. Soluble sugar and starch contents were higher in plants from the low-elevation habitat than in those from the high-elevation habitat independently of the water level. Therefore, P. hydropiper plants from the low-elevation habitat exhibit a lower growth rate and more conservative energy strategy to cope with flooding in comparison with plants from the high-elevation habitat. These different adaptive strategies to tolerate flooding among $P$. hydropiper populations may potentially drive ecotype differentiation within this species along flooding gradients.

\section{AUTHOR CONTRIBUTIONS}

$\mathrm{X}$-SC and Y-FL wrote the manuscript and executed the technical assays and statistical analyses. X-SC and Y-HX designed the experiments and edited the manuscript. Y-HC, Z-YH, Z-MD, and FL contributed to data collection and interpretation. All authors reviewed the manuscript.

\section{FUNDING}

This work was supported by the National Natural Science Foundation of China (31770471 and 41401290) and the National Pilot Project on the Remediation of Heavy-Metal-Contaminated Farmland Soils.

Edwards, A. L., Lee, D. W., and Richard, J. H. (2003). Response to fluctuating environment: effect of water depth on growth and biomass allocation in Eleocharis cellulosa Torr. (Cyperaceae). Can. J. Bot. 81, 964-975. doi: 10.1139/ b03-091

Ferreira, C. S., Piedade, M. T. F., Franco, A. C., Gonçalves, J. F. C., and Junk, W. J. (2009). Adaptive strategies to tolerate prolonged flooding in seedlings of floodplain and upland populations of Himatanthus sucuuba, a Central Amazon tree. Aquat. Bot. 90, 246-252. doi: 10.1016/j.aquabot.2008.10.006

Lenssen, J. P. M., and de Kroon, H. (2005). Abiotic constraints at the upper boundaries of two Rumex species on a freshwater flooding gradient. J. Ecol. 93, 138-147. doi: 10.1111/j.1365-2745.2004.00957.x

Lenssen, J. P. M., van Kleunen, M., Fischer, M., and de Kroon, H. (2004). Local adaption of the clonal plant Ranuculus reptans to flooding along a small-scale gradient. J. Ecol. 92, 696-706. doi: 10.1111/j.0022-0477.2004.00895.x

Li, A. J., Bao, B. J., Grabovskaya-Borodina, A. E., Hong, S. P., McNeill, J. M., Mosyakin, S. L., et al. (2003). Flora of China (Polygonaceae). Beijing: Science Press.

Li, Y. F., Chen, X. S., Xiang, W. H., and Xie, Y. H. (2016). Effects of water levels on the growth and reproductive characteristics of Carex brevicuspis growing on sites with different elevations. Acta Ecol. Sin. 36, 1959-1966.

Luo, W. B., Song, F. B., and Xie, Y. H. (2008). Trade-off between tolerance to drought and tolerance to flooding in three wetland plants. Wetlands 28, 866-873. doi: 10.1672/07-225.1

Macek, P., Rejmankova, E., and Houdkova, K. (2006). The effect of long-term submergence on functional properties of Eleocharis cellulose. Torr. Aquat. Bot. 84, 251-258. doi: 10.1016/j.aquabot.2005.11.003

Manzur, M. E., Grimoldi, A. A., Insauti, P., and Striker, G. G. (2009). Escape from water or remain quiescent? Lotus tenuis changes its strategy depending on depth of submergence. Ann. Bot. 104, 1163-1169. doi: 10.1093/aob/mcp203

McKone, M. J., and Lively, C. M. (1993). Statistical analysis of experiments conducted at multiple sites. Oikos 67, 184-186.

Mollard, F. P. O., Striker, G. G., Ploschuk, E. L., and Insausti, P. (2010). Subtle topographical differences along a floodplain promotes different plant strategies among Paspalum dilatatum subspecies and 
populations. Austral Ecol. 35, 189-196. doi: 10.1111/j.1442-9993.2009. 02026.X

Pan, Y., Xie, Y. H., Deng, Z. M., Tang, Y., and Pan, D. D. (2014). High water level impedes the adaptation of Polygonum hydropiper to deep burial: responses of biomass allocation and root morphology. Sci. Rep. 4:e5612. doi: 10.1038/ srep05612

Pierik, R., van Aken, J. M., and Voesenek, L. A. C. J. (2009). Is elongationinduced leaf emergence beneficial for submerged Rumex species? Ann. Bot. 103, 353-357. doi: 10.1093/aob/mcn 143

Qin, X. Y., Li, F., Chen, X. S., and Xie, Y. H. (2013). Growth responses and non-structural carbohydrates in three wetland macrophyte species following submergence and de-submergence. Acta Physiol. Plant. 35, 2609-2274. doi: 10.1007/s11738-013-1241-x

Ram, P. C., Singh, B. B., Singh, A. K., Ram, P., Singh, P. N., Singh, H. P., et al. (2002). Submergence tolerance in rainfed lowland rice: physiological basis and prospects for cultivar improvement through markeraided breeding. Field Crops Res. 76, 131-152. doi: 10.1016/S0378-4290(02)00 035-7

Sauter, M. (2000). Rice in deep water: 'how to take heed against a sea of troubles'. Naturwissenschaften 87, 289-303. doi: 10.1007/s001140050725

Setter, T. L., and Laureles, E. V. (1996). The beneficial effect of reduced elongation growth on submergence tolerance of rice. J. Exp. Bot. 47, 1551-1559. doi: $10.1093 / j x b / 47.10 .1551$

Sokal, R. R., and Rohlf, F. J. (1981). Biometry, 2nd Edn. New York, NY: W.H. Freeman \& Company.

Striker, G. G., Izaguirre, R. F., Manzur, M. E., and Grimoldi, A. A. (2012). Different strategies of Lotus japonicus, L. corniculatus and L. tenuis to deal with complete submergence at seedling stage. Plant Biol. 14, 50-55. doi: 10.1111/j.1438-8677. 2011.00493.x

van Eck, W. H. J. M., van de Steeg, H. M., Blom, C. W. P. M., and de Kroon, H. (2004). Is tolerance to summer flooding correlated with distribution patterns in river floodplain? A comparative study of 20 terrestrial grassland species. Oikos 107, 393-405. doi: 10.1111/j.0030-1299.2004.13083.x

Vervuren, P. J. A., Blom, C. W. P. M., and de Kroon, H. (2003). Extreme flooding events on the Rhine and the survival and distribution of riparian plant species. J. Ecol. 91, 135-146. doi: 10.1046/j.1365-2745.2003.00749.x

Voesenek, L. A. C. J., Colmer, T. D., Pierik, R., Millenaar, F. F., and Peeters, A. J. M. (2006). How plants cope with complete submergence. New Phytol. 170, 213-226. doi: 10.1111/j.1469-8137.2006.01692.x

Xie, Y. H., and Chen, X. S. (2008). Effects of three-gorge project on succession of wetland vegetation in dongting lake. Res. Agric. Mod. 29, 684-687.

Xie, Y. H., Ren, B., and Li, F. (2009). Increased nutrient supply facilitates acclimation to high-water level in the marsh plant Deyeuxia angustifolia: the response of root morphology. Aquat. Bot. 91, 1-5. doi: 10.1016/j.aquabot.2008. 12.004

Yemm, E., and Willis, A. (1954). The estimation of carbohydrates in plant extracts by anthrone. Biochem. J. 57, 508-514. doi: 10.1042/bj0570508

Zhang, Q., Peters, J., Visser, E., de Kroon, H., and Huber, H. (2016). Hydrologically contrasting environments induce genetic but not phenotypic differentiation in Solanum dulcamara. J. Ecol. 104, 1649-1661. doi: 10.1111/1365-2745.12648

Conflict of Interest Statement: The authors declare that the research was conducted in the absence of any commercial or financial relationships that could be construed as a potential conflict of interest.

Copyright (C) 2019 Chen, Li, Cai, Xie, Deng, Li and Hou. This is an open-access article distributed under the terms of the Creative Commons Attribution License (CC BY). The use, distribution or reproduction in other forums is permitted, provided the original author(s) and the copyright owner(s) are credited and that the original publication in this journal is cited, in accordance with accepted academic practice. No use, distribution or reproduction is permitted which does not comply with these terms. 